\title{
Synthesis of (-)-Conduramine A1, (-)-Conduramine A2 and (-)- Conduramine E2 in Six Steps from Cyclohexa-1,4-diene
}

\author{
Solange Da Silva Pinto, Stephen G. Davies, * Ai M. Fletcher, Paul M. Roberts, and James E. Thomson \\ Department of Chemistry, Chemistry Research Laboratory, University of Oxford, Mansfield Road, Oxford OX1 3TA, U.K. \\ Supporting Information Placeholder
}<smiles>N[C@H]1C=CC(O)[C@@H](O)[C@H]1O</smiles><smiles>N[C@H]1C(O)C=CC(O)[C@H]1O</smiles><smiles>N[C@H]1C(O)C=CC(O)[C@H]1O</smiles>

()-Conduramine A1

( )-Conduramine A2

( )-Conduramine E2

\begin{abstract}
A method to enable the synthesis of conduramines and their $N$-substituted derivatives (enantiopure or racemic form) in six steps (five steps for $N$-substituted derivatives) from cyclohexa-1,4-diene is reported. Key features of this reaction sequence include a preparation of benzene oxide that is amenable to multigram scale, and its efficient ring-opening upon treatment with a primary amine. Epoxidation of the resultant amino alcohols $\left(40 \% \mathrm{aq}_{\mathrm{HBF}}\right.$ then $\left.m-\mathrm{CPBA}\right)$ is accompanied by hydrolytic ringopening in situ to give the corresponding $N$-substituted conduramine derivatives directly. These may undergo subsequent $N$ deprotection to give the parent conduramines, as demonstrated by the preparation of enantiopure (-)-conduramine A1, (-)conduramine A2 and (-)-conduramine E2 (the latter two for the first time). The selectivity of the epoxidation reaction is proposed to be the result of competitive ammonium-directed and hydroxyl-directed epoxidation processes, followed by either direct $\left(\mathrm{S}_{\mathrm{N}} 2\right.$ type) or conjugate $\left(\mathrm{S}_{\mathrm{N}} 2^{\prime}\right.$-type) ring-openings of the intermediate epoxides.
\end{abstract}

Conduramines are derivatives of conduritols (cyclohexa-5ene-1,2,3,4-tetraols) $\mathbf{1}$ in which one of the hydroxyl functionalities has been replaced by an amino functionality. ${ }^{1}$ They have attracted interest due to their often potent biological activity as selective glycosidase inhibitors, a class of enzymes which are involved with the progression of a number of diseases. ${ }^{1}$ The residue of conduramine $\mathrm{F} 1$, for example, is found as a sub-structural unit within acarbose (glucobay) 2, a drug used for the treatment of type 2 diabetes mellitus. ${ }^{2}$ This property of the conduramines has resulted in a significant amount of investigation being lavished on them. Interestingly, it has been found that derivatives of conduramines often possess enhanced biological activity over that of the parents, and for example (-)-conduramine B1 3 itself has been shown to lack any inhibitory activity against a range of glycosidases, whilst the corresponding $N$-benzyl derivative 4 was found to display selective activity. ${ }^{3}$ To further the interest in these compounds, a number of natural products containing the conduramine core are also known, including the Amaryllidaceae alkaloids narciclasine $5^{4}$ and lycoricidine $6,{ }^{5}$ both of which contain the residue of conduramine A1 as a sub-structural unit and possess desirable biological activity (Figure 1).<smiles>O=C(O)C1C=CC(O)C(O)C1O</smiles><smiles>N[C@H]1C=C[C@@H](O)[C@H](O)[C@@H]1O</smiles>

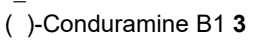<smiles>O[C@H]1C=C[C@@H](NCc2ccccc2)[C@H](O)[C@@H]1O</smiles>
N-Benzyl conduramine B1 4

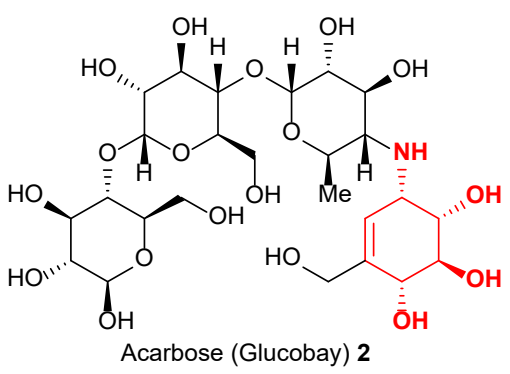<smiles>[R]c1c2c(cc3c1C(=O)N[C@H]1C3=C[C@@H](O)[C@@H](O)[C@H](O)[C@H]1O)OCO2</smiles>

Narciclasine 5, $\mathrm{R}=\mathrm{OH}$ Lycoricidine 6, $\mathrm{R}=\mathrm{H}$

Figure 1. Structures of conduritol 1, acarbose (glucobay) 2, (-)conduramine B1 3, $N$-benzyl conduramine B1 4, narciclasine 5 and lycoricidine $\mathbf{6}$.

The only source of these biologically interesting amino polyols is by means of laboratory synthesis, as none of the conduramine family themselves are naturally occurring. ${ }^{1}$ Unsurprisingly, therefore, several routes to these compounds and their derivatives have been reported, although these are often rather lengthy and give rise to only one or two conduramine prod- 
ucts. ${ }^{1,6}$ Given our previous experience concerning the synthesis of dihydroconduramines, ${ }^{7-9}$ we proposed that epoxidation (treatment with $\mathrm{H}^{+}$then $m$-CPBA) of allylic amino alcohols 7 , derived from the ring-opening of benzene oxide, would give the corresponding ring-opened products $\mathbf{8}$ and $\mathbf{9}$, i.e., conduramines $(\mathrm{R}=\mathrm{H})$ or their $N$-protected derivatives $(\mathrm{R} \neq \mathrm{H})$ directly. This approach to these compounds would be attractive in that it may allow preparation of several diastereoisomers of the targets for biological profiling in very short order, and in any case would provide further insight into the relative abilities of the ammonium functionality versus the hydroxyl functionality to direct the epoxidation reaction. ${ }^{10}$ Herein we report our preliminary findings within this area which culminate in the preparation of the racemic $N$-benzyl derivatives of conduramines $\mathrm{A} 1, \mathrm{~A} 2$ and $\mathrm{E} 2$, and the enantiopure conduramines $(-)$-A-1 (-)-A2 and (-)-E2 themselves, in six steps or fewer from cyclohexa-1,4,-diene in each case (Figure 2).

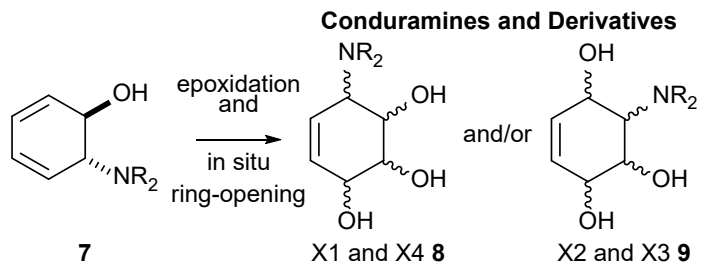

Figure 2. Proposed synthesis of conduramines and their derivatives 8 and 9 from allylic amino alcohols 7.

Our first goal was the development of a synthesis of benzene oxide amenable to scale-up, which was achieved by modification of the method first reported by Günther. ${ }^{11}$ Treatment of cyclohexa-1,4-diene 10 with $\mathrm{AcOOH}$ in $\mathrm{CH}_{2} \mathrm{Cl}_{2}$ gave cyclohexa-1,4-diene monoepoxide 11 in $66 \%$ yield. Treatment of 11 with $\mathrm{Br}_{2}$ in a mixture of $\mathrm{CH}_{2} \mathrm{Cl}_{2}$ and $\mathrm{CHCl}_{3}$ delivered dibromide 12 in $91 \%$ yield ( $60 \%$ overall yield from 10). When these two steps were telescoped, diluting the initial reaction mixture with $\mathrm{CHCl}_{3}$ and adding $\mathrm{Br}_{2}$ to the same reaction flask (i.e., obviating the isolation and purification of 11), dibromide 12 was isolated in $88 \%$ overall yield from 10, on multigram scale. Final treatment of $\mathbf{1 2}$ with $\mathrm{DBU}$ in $\mathrm{Et}_{2} \mathrm{O}$ gave benzene oxide 13 in 54\% yield; this was generated, isolated and immediately used, as required (Scheme 1).

\section{Scheme 1. Large Scale Preparation of Benzene Oxide 13}

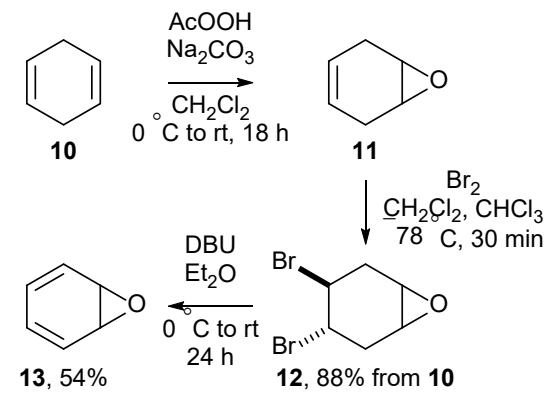

Benzene oxide 13 remains an under-utilized building block in synthesis, and for example its ring-opening has been surprisingly little explored. ${ }^{12}$ We chose the ring-opening of $\mathbf{1 3}$ using benzylamine as a model system. Problems encountered were lack of reactivity, or promotion of an undesired rearrangement pathway giving phenol 15. However, after optimization (variation of solvent, time, temperature, and the presence of Lewis acids) it was found that treatment of $\mathbf{1 3}$ with benzylamine in $\mathrm{MeOH}$ at $66^{\circ} \mathrm{C}$ gave allylic amino alcohol 14 almost exclusively, and as a single diastereoisomer ( $>95: 5 \mathrm{dr})$, with only trace amounts $(<5 \%)$ of phenol 15 being formed, and upon purification 14 was isolated in $90 \%$ yield. The relative configuration within $\mathbf{1 4}$ could be confidently assigned as trans, due to the diagnostically large value of the ${ }^{1} \mathrm{H}$ NMR ${ }^{3} \mathrm{~J}$ coupling constant $\left({ }^{3} J=12.1 \mathrm{~Hz}\right)$ between the protons attached to the two stereogenic centers (Scheme 2).

\section{Scheme 2. Preparation of Allylic Amino Alcohol 14}

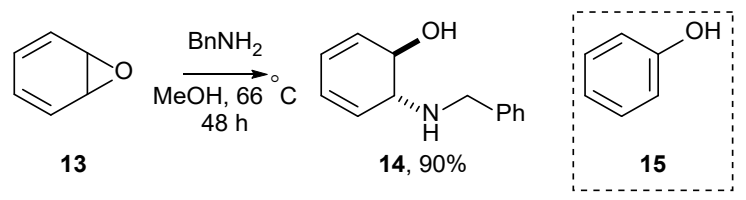

Treatment of 14 with $40 \%$ aq $\mathrm{HBF}_{4}$ and then $m$-CPBA gave a 21:36:31:12 mixture of four compounds, subsequently identified as $N$-benzyl conduramine A1 (18), $N$-benzyl conduramine A2 (19), $N$-benzyl conduramine E2 (20), and $N$-benzyl conduramine F2 (21), respectively. Purification by preparatory t.l.c. gave 18 in $8 \%$ yield, 19 in $23 \%$ yield, 20 in $18 \%$ yield and an impure sample of $\mathbf{2 1}$ in $~ 5 \%$ yield, as single diastereoisomers $(>95: 5 \mathrm{dr})$ in each case (Scheme 3$)$. The gross structures of 18-21 were assigned by analyses of the typical range of $1 \mathrm{D}$ and 2D NMR spectra, whilst their relative configurations were subsequently established following treatment of each of 18-21 with $\mathrm{H}_{2}$ in the presence of $\mathrm{Pd}(\mathrm{OH})_{2} / \mathrm{C}$, which effected tandem hydrogenation of the olefin functionality and hydrogenolytic removal of the $N$-benzyl group to give the corresponding dihydroconduramines A1 (22), A2 (23), ${ }^{8}$ E2 (24) $)^{9}$ and F2 (25), ${ }^{9,13}$ the samples of $23-25$ gave ${ }^{1} \mathrm{H}$ and ${ }^{13} \mathrm{C}$ NMR spectra that matched with those previously reported ${ }^{8,9}$ (thus confirming their identities, and hence the identities of 19-21), whilst diagnostic values of the ${ }^{1} \mathrm{H}$ NMR ${ }^{3} J$ coupling constants observed for $\mathbf{2 2}$ allowed its relative configuration (and thence that of 18) to be confidently assigned. The observation of the four products $\mathbf{1 8 - 2 1}$ is consistent with monoepoxidation of the diene functionality within 14 being followed by a hydrolytic ring-opening reaction. In order to gain some insight into the precise details of the mechanism, the reaction was repeated using $\mathrm{HBF}_{4} \cdot \mathrm{OEt}_{2}$ in $\mathrm{H}_{2}{ }^{18} \mathrm{O}\left(\geq 98 \%{ }^{18} \mathrm{O}\right)$ in place of $40 \%$ aq $\mathrm{HBF}_{4}$, which resulted in formation of the same four compounds in the same ratio (within experimental error), labelled with a single ${ }^{18} \mathrm{O}$ atom $(92 \%$ incorporation of an ${ }^{18} \mathrm{O}$ label in each case, as judged by mass spectrometric analysis). The nature of fragmentation of these compounds rendered mass spectrometry unsuitable as a tool to locate the position of the ${ }^{18} \mathrm{O}$ label and therefore analysis of ${ }^{16} \mathrm{O} /{ }^{18} \mathrm{O}$ isotope induced chemical shifts ${ }^{14}$ in the ${ }^{13} \mathrm{C}$ NMR spectrum were employed to unambiguously locate the ${ }^{18} \mathrm{O}$ atom within each of these samples of 18-21: $>95 \%$ incorporation of the ${ }^{18} \mathrm{O}$ label was observed at $\mathrm{C}(1)$ in all cases, with all other positions showing negligible $(<5 \%)$ incorporation of the label (Scheme 3 ). On the basis of these results, the following mechanistic hypothesis is proposed. As one of the olefins bears an allylic hydroxyl functionality and the other an allylic $N$-benzylamino functionality, both of which are known to be able to direct the olefinic epoxidation reaction to the proximal (syn) face in a six-membered ring-system (presumably by formation of a hydrogen-bond in the transition state),${ }^{15}$ the rate of background (non-directed epoxidation) was expected to be so low as to be a negligible contributor to the selectivity observed in the epoxidation step. Thus, out of the four possible regio- and diastere- 
oisomeric products resulting from monoepoxidation of $\mathbf{1 4}$, it is expected that only $\mathbf{1 6}$ (resulting from direction by the hydroxyl group) and 17 (resulting from direction by the $N$ benzylammonium group) are formed as intermediates in this reaction. Regioselective ring-opening of $\mathbf{1 6}$ in an $\mathrm{S}_{\mathrm{N}} 2$-type fashion (with inversion of configuration) gives 18, and an analogous process for 17 gives 19. Competitive $S_{\mathrm{N}}$ '-type ringopening of epoxide $\mathbf{1 7}$ would result in the formation of $\mathbf{2 0}$ and 21. Although both $\mathrm{S}_{\mathrm{N}} 1^{\prime}$-type and $\mathrm{S}_{\mathrm{N}} 2^{\prime}$-type hydrolytic ringopening of 17 could give rise to $\mathbf{2 0}$ and 21 as a mixture of epimers, ${ }^{16}$ it is proposed that the latter (i.e., $\mathrm{S}_{\mathrm{N}} 2^{\prime}$-type process) is more likely in operation, as we have observed no evidence of a predilection towards formation of a cation intermediate in any of the examples of this reaction that we have previously studied. ${ }^{17}$ Importantly, the lack of incorporation of the ${ }^{18} \mathrm{O}$ label at $\mathrm{C}(4)$ within $\mathbf{2 0}$ indicated that $\mathrm{S}_{\mathrm{N}}$-type hydrolytic ringopening of epoxide 16 was a negligible contributor to the production of $\mathbf{2 0}$ in this reaction. Assuming this mechanistic rationale, the ratio of the intermediate epoxides $\mathbf{1 6}$ and $\mathbf{1 7}$ in this reaction is therefore represented by the ratio $18:(\mathbf{1 9}+\mathbf{2 0}+\mathbf{2 1})$, i.e., approximately 1:4, which is a measure of the relative directing abilities of the two functionalities in this specific instance (Scheme 3 ). The superior ability of the $N$-benzylamino substituent versus the hydroxyl substituent to direct the epoxidation reaction (i.e., promote a faster reaction) is consistent with our previous observations in a related system. ${ }^{10}$

Scheme 3. Preparation of Racemic N-Benzyl Conduramines A1 (18), A2 (19), E2 (20) and F2 (21)

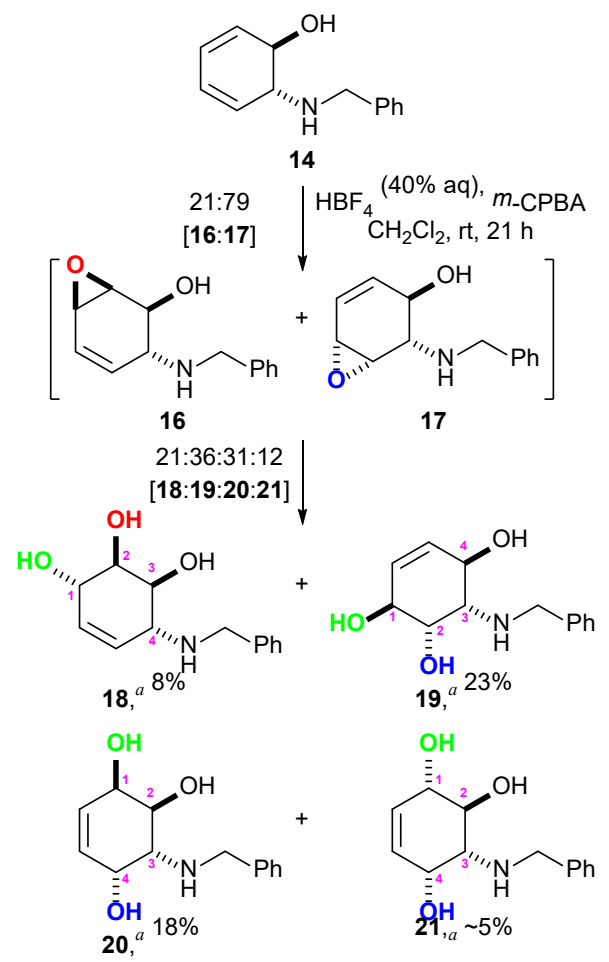

${ }^{a}$ The positions of the ${ }^{18} \mathrm{O}$ labels when run with $\mathrm{H}_{2}{ }^{18} \mathrm{O}$ (see text) are shown in green; the proposed positions of the oxygen atoms derived from $m$-CPBA are shown in either red (for $\mathbf{1 6}$ and derivatives) or blue (for $\mathbf{1 7}$ and derivatives) for clarity. IUPAC numbering of 18-21 is also shown.

With a route to racemic conduramine derivatives in hand, a route to enantiopure materials was investigated. Ring-opening of benzene oxide 13 upon treatment with enantiopure $(R)-\alpha-$ methyl- $p$-methoxybenzylamine gave a mixture of two compounds, 26 and 27, in an approximate 50:50 ratio-thus showing no propensity for desymmetrisation under these conditions, as expected. ${ }^{18}$ These compounds were separated chromatographically to give 26 in 19\% yield and 27 in $21 \%$ yield, along with a mixed fraction in $21 \%$ combined yield (Scheme 4). The relative configuration within 27 was unambiguously assigned by single crystal X-ray diffraction analysis, ${ }^{19}$ with the absolute configuration following from the known $(R)$ configuration of the $\alpha$-stereocenter (Figure 3 ). The dihedral angle between the two protons on the two stereogenic centers in the solid state was $175^{\circ}$ and, as before, the large value of the ${ }^{1} \mathrm{H}$ NMR ${ }^{3} J$ coupling constant $\left({ }^{3} J=12.9 \mathrm{~Hz}\right)$ between these protons was consistent with an analogous conformation being favored in solution and also indicative of the trans relative configuration. On this basis, $\mathbf{2 6}$ was assigned as the alternative trans diastereoisomer that would result from ring-opening of the meso-epoxide $\mathbf{1 3}$ by the enantiopure nucleophile; the large value of the ${ }^{1} \mathrm{H}$ NMR ${ }^{3} J$ coupling constant $\left({ }^{3} J=11.5 \mathrm{~Hz}\right)$ between the protons on the two stereogenic centers was supportive of this assignment. ${ }^{20}$

Scheme 4. Preparation of Allylic Amino Alcohols 26 and 27

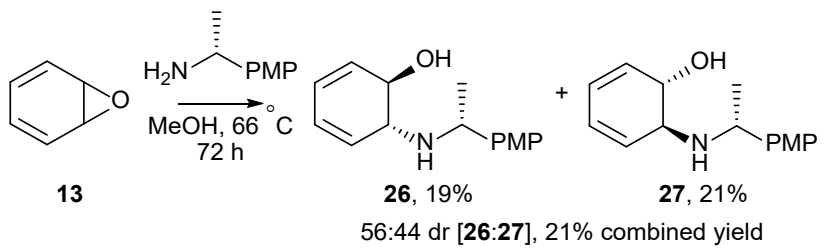

$\mathrm{PMP}=$ para-methoxyphenyl

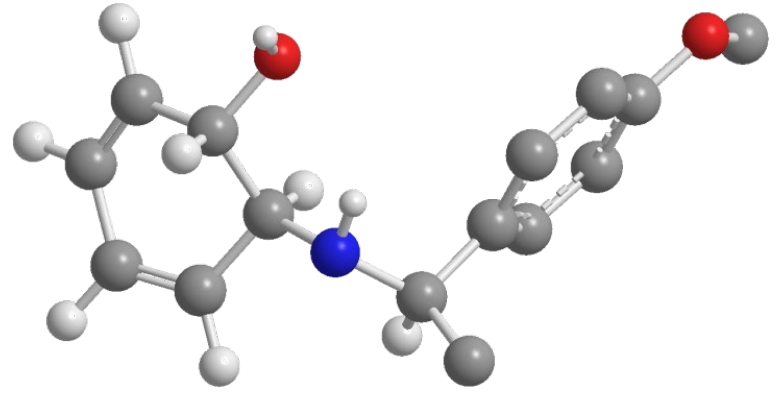

Figure 3. X-ray crystal structure of 27 (selected $\mathrm{H}$ atoms have been omitted for clarity).

Allylic amino alcohol $\mathbf{2 6}$ was arbitrarily selective for elaboration to the corresponding conduramines (as $\mathbf{2 6}$ and 27 may be considered as pseudoenantiomeric for this purpose). Treatment of 26 with $40 \%$ aq $\mathrm{HBF}_{4}$ and then $m$-CPBA gave a 17:37:32:14 mixture of four compounds, identified as $N-\alpha-$ methyl- $p$-methoxybenzyl conduramine A1 (30), $N$ - $\alpha$-methyl$p$-methoxybenzyl conduramine A2 (31), $N$ - $\alpha$-methyl- $p$ methoxybenzyl conduramine E2 (32), and $N$ - $\alpha$-methyl- $p$ methoxybenzyl conduramine F2 (33), respectively. Purification by preparatory t.l.c. gave $\mathbf{3 0}$ in $8 \%$ yield, $\mathbf{3 1}$ in $21 \%$ yield, 32 in 15\% yield and an impure sample of $\mathbf{3 3}$ in $~ 5 \%$ yield, as single diastereoisomers ( $>95: 5 \mathrm{dr})$ in each case. As before, the gross structures of 30-33 were assigned by analyses of the typical range of $1 \mathrm{D}$ and 2D NMR spectra and the relative configurations within 31-33 were thence assigned on the basis of the similarities between their ${ }^{1} \mathrm{H}$ NMR ${ }^{3} J$ coupling constants and those of the corresponding products 19-21 derived from amino alcohol 14. ${ }^{13}$ The absolute configurations then followed 
from the known absolute configurations of the stereocenters derived from the trans-amino alcohol $\mathbf{2 6}$. The relative configuration within $\mathbf{3 0}$, meanwhile, was subsequently assigned (vide infra). As the ratio of $\mathbf{3 0 - 3 3}$ is the same (within experimental error) as the ratio of the corresponding products 18-21 generated when 14 was subjected to the same reaction conditions, analogous mechanisms to rationalize formation of each of $\mathbf{3 0}$ 33 from amino alcohol 26 may be surmised (Scheme 5).

Scheme 5. Preparation of Enantiopure $N$ - $\alpha$-Methyl-pmethoxybenzyl Conduramines A1 (30), A2 (31), E2 (32) and F2 (33)

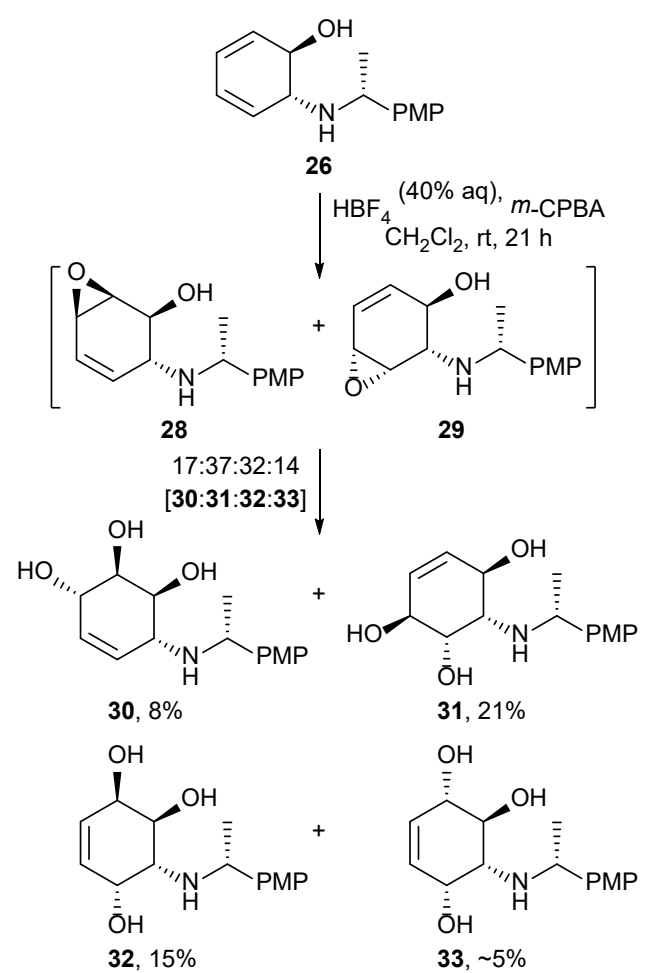

Finally, treatment of 30-32 with $\mathrm{Et}_{3} \mathrm{SiH}$ in the presence of TFA effected removal of the $\alpha$-methyl- $p$-methoxybenzyl fragment to give (-)-conduramine A1 (34), (-)-conduramine A2 (35) and (-)-conduramine E2 (36), in $82 \%, 79 \%$ and $58 \%$ yield, respectively, and in $>95: 5 \mathrm{dr}$ in each case. The former, (-)-conduramine A1 (34), has been previously described ${ }^{21}$ (as has its antipode $)^{22}$ and thus the relative and absolute configurations of $\mathbf{3 0}$ were secured. The latter two, (-)-conduramine A2 (35) and (-)-conduramine E2 (36), have not been previously described (Scheme 6).
Scheme 6. Preparation of Enantiopure Conduramines (-)A1 (34), (-)-A2 (35), and (-)-E2 (36)<smiles>C[C@H](N[C@@H]1C=C[C@@H](O)[C@@H](O)[C@@H]1O)P(=O)=O</smiles>

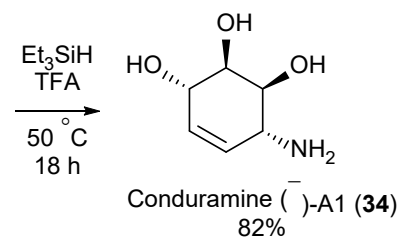<smiles>C[C@H](N)N[C@@H]1[C@H](O)[C@H](O)C=C[C@H]1O</smiles>

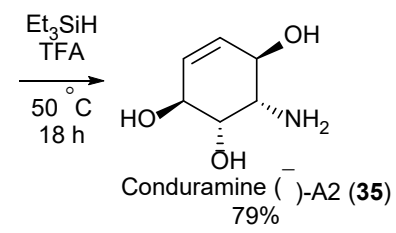<smiles>C[C@H](N)N[C@H]1[C@@H](O)C=C[C@H](O)[C@H]1O</smiles>

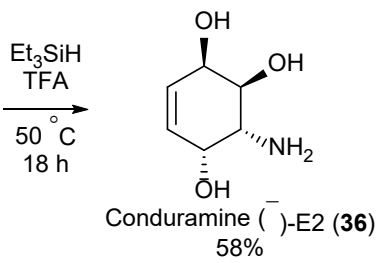

In conclusion, the synthesis of a range of conduramines and their $N$-protected derivatives has been achieved in very short order from cyclohexa-1,4-diene. The key steps of the process involve formation of benzene oxide and its ring-opening with a primary amine. Epoxidation $\left(\mathrm{HBF}_{4}\right.$ then $m$-CPBA) of the resultant allylic amino alcohols is controlled by hydrogenbonding to either the allylic hydroxyl functionality or the in situ formed allylic $N$-benzylammonium moiety, with the latter being superior over the former in its ability to promote epoxidation of the proximal olefin. Hydrolytic ring-opening of the resultant epoxide intermediates occurs in situ, via either a direct $\left(\mathrm{S}_{\mathrm{N}} 2\right.$-type $)$ process or a conjugate $\left(\mathrm{S}_{\mathrm{N}} 2^{\prime}\right.$-type $)$ process, giving a mixture of the corresponding amino triol products. Despite the modest diastereoselectivity of the epoxidation reactions and multiple hydrolytic ring-opening reactions resulting in production of mixtures of isomeric products, the low step-count results in overall yields which are comparable or better than those of other multi-step processes, as well as allowing rapid production of unknown conduramines and derivatives for biological profiling - these derivatives may display biological activity superior to those of the parent compounds. In the case of an $N$ - $\alpha$-methyl- $p$-methoxybenzyl protecting group, the corresponding enantiopure conduramines may be accessed upon deprotection. Further investigations, including investigation of the diastereoselectivity of the epoxidation reaction itself, are currently ongoing in our laboratory and these results will be reported in due course.

\section{ASSOCIATED CONTENT}

\section{Supporting Information}

The Supporting Information is available free of charge on the ACS Publications website at DOI: 10.1021/acs.orglett. Xxxxxx.

Experimental details, characterization data, and copies of ${ }^{1} \mathrm{H}$ and ${ }^{13} \mathrm{C}$ NMR spectra (PDF)

\section{AUTHOR INFORMATION}

\section{Corresponding Author}


*E-mail: steve.davies@chem.ox.ac.uk.

\section{Notes}

The authors declare no competing financial interest.

\section{REFERENCES} 2733.

(1) For a review, see: Łysek, R.; Vogel, P. Tetrahedron 2006, 62,

(2) DiNicolantonio, J. J.; Bhutani, J.; O'Keefe, J. H. Open Heart 2015, 2, 327. 3071 .

(3) Łysek, R.; Schu, C.; Vogel, P. Bioorg. Med. Chem. 2005, 15,

(4) Ceriotti, G. Nature 1967, 213, 595.

(5) Okamoto, T.; Torii, Y.; Isogai, Y. Chem. Pharm. Bull. 1968, 16,1860 .

(6) For selected, more recent examples of syntheses of conduramines and their $N$-substituted derivatives, see: (a) Chang, Y.-K.; Lo, H.-J.; Yan, T.-H. J. Chin. Chem. Soc. 2010, 57, 24. (b) Lu, P.-H.; Yang, C.-S.; Devendar, B.; Liao, C.-C. Org. Lett. 2010, 12, 2642. (c) Kuno, S.; Higaki, K.; Takahashi, A.; Nanbaband, E.; Ogawa S. Med. Chem. Commun. 2015, 6, 306. (d) Myeong, I.-S.; Kim, J.-S. Lee, Y.T.; Kang, J.-C.; Park, S.-H.; Jung, C.; Ham, W.-H. Tetrahedron: Asymmetry 2016, 27, 823. (e) Harit, V. K.; Ramesh, N. G. J. Org. Chem. 2016, 81, 11574. (f) Prasad, K. R. Tetrahedron 2018, 74, 6689. (g) Harita, V. K.; Ramesh, N. G. Org. Biomol. Chem. 2019, 17, 5951.

(7) Brennan, M. B.; Csatayová, K.; Davies, S. G.; Fletcher, A. M.; Green, W. D.; Lee, J. A.; Roberts, P. M.; Russell, A. J.; Thomson, J. E. J. Org. Chem. 2015, 80, 6609.

(8) Da Silva Pinto, S.; Davies, S. G.; Fletcher, A. M.; Roberts, P. M.; Thomson, J. E. Synthesis 2018, 50, 64.

(9) Da Silva Pinto, S.; Davies, S. G.; Fletcher, A. M.; Roberts, P. M.; Thomson, J. E. J. Org. Chem. 2018, 83, 9939.

(10) Brennan, M. B.; Davies, S. G.; Fletcher, A. M.; Lee, J. A.; Roberts, P. M.; Russell, A. J.; Thomson, J. E. Aust. J. Chem. 2015, 68,610 . 385.

(11) Vogel, E.; Günther, H. Angew. Chem. Int. Ed. Engl. 1967, 6,

(12) For example, see: (a) DeMarinis, R. M.; Berchtold, G. A. J. Am. Chem. Soc. 1969, 91, 6525. (b) Jeffrey, A. M.; Yeh, H. J. C.; Jerina, D. M.; De Marinis, R. M.;Foster, C. H.; Piccolo, D. E.; Berchtold, G. A. J. Am. Chem. Soc. 1974, 96, 6929. (c) Rastetter, W. H.; Chancellor, T.; Richard, T. J. J. Org. Chem. 1982, 47, 1509-1512. (d) Bertozzi, F.; Crotti, P.; Del Moro, F.; Feringa, B. L.; Macchia, F.; Pineschi, M. Chem. Commun. 2001, 2606.

(13) Further details are contained within the SI.

(14) For a review of isotope effects in nuclear shielding, see: Hansen, P. E. Prog. Nucl. Magn. Reson. Spectrosc. 1988, 20, 207.

(15) Davies, S. G. Davies; Fletcher, A. M.; Thomson, J. E. Org. Biomol. Chem. 2014, 12, 4544.

(16) Unlike $\mathrm{S}_{\mathrm{N}} 2$-type processes, $\mathrm{S}_{\mathrm{N}} 2$ '-type processes are known to be non-stereospecific; see: Smith, M. B. March's Advanced Organic Chemistry: Reactions, Mechanisms, and Structure, 7th ed.; John Wiley \& Sons Inc.: Hoboken, New Jersey, 2013.

(17) See Refs 6-10 and 15, and references contained therein.

(18) For the related ring-opening of racemic 3,4-epoxycyclohexene with a chiral amine, see: Knapp, S.; Sebastian, M. J.; Ramanathan, H.; Bharadwaj, P.; Potenza, J. A. Tetrahedron 1986, 42, 3405-3410.

(19) Crystallographic data (excluding structure factors) have been deposited with the Cambridge Crystallographic Data Centre as supplementary publication number CCDC 1940566.

(20) These data also add further support to the assignment of the trans relative configuration of $\mathbf{1 4}$.

(21) Myeong, I.-S.; Kim, J.-S.; Lee, Y.-T.; Kang, J.-C.; Park, S.-H.; Jung, C.; Ham, W.-H. Tetrahedron: Asymmetry 2016, 27, 823.

(22) Norsikian, S.; Soulé, J.-F.; Cannillo, A.; Guillot, R.; Tran Huu Dau, M.-E.; Beau, J.-M. Org. Lett. 2012, 14, 544. 